\title{
Melanoma risk perception and prevention behavior among African-Americans: the minority melanoma paradox
}

This article was published in the following Dove Press journal:

Clinical, Cosmetic and Investigational Dermatology

5 August 2015

Number of times this article has been viewed

\author{
Alina Goldenberg' \\ Igor Vujic ${ }^{2,3}$ \\ Martina Sanlorenzo ${ }^{2,4}$ \\ Susana Ortiz-Urda ${ }^{2}$ \\ 'Department of Internal Medicine/ \\ Dermatology, University of California, \\ San Diego, ${ }^{2}$ Mt Zion Cancer Research \\ Center, University of California San \\ Francisco, San Francisco, CA, USA; \\ ${ }^{3}$ Department of Dermatology, The \\ Rudolfstiftung Hospital, Academic \\ Teaching Hospital, Medical University \\ Vienna, Vienna, Austria; ${ }^{4}$ Section of \\ Dermatology, Department of Medical \\ Sciences, University of Turin, Turin, \\ Italy
}

Introduction: Melanoma is the most deadly type of skin cancer with $75 \%$ of all skin cancer deaths within the US attributed to it. Risk factors for melanoma include ultraviolet exposure, genetic predisposition, and phenotypic characteristics (eg, fair skin and blond hair). Whites have a 27-fold higher incidence of melanoma than African-Americans (AA), but the 5-year survival is $17.8 \%$ lower for AA than Whites. It is reported continuously that AA have more advanced melanomas at diagnosis, and overall lower survival rates. This minority melanoma paradox is not well understood or studied.

Objective: To explore further, the possible explanations for the difference in melanoma severity and survival in AA within the US.

Methods: Qualitative review of the literature.

Results: Lack of minority-targeted public education campaigns, low self-risk perception, low self-skin examinations, intrinsic virulence, vitamin D differences, and physician mistrust may play a role in the melanoma survival disparity among AA.

Conclusion: Increases in public awareness of melanoma risk among AA through physician and media-guided education, higher index of suspicion among individuals and physicians, and policy changes can help to improve early detection and close the melanoma disparity gap in the future.

Keywords: acral, advanced, African-American, disparity, melanoma, survival

\section{Introduction}

Melanoma is the deadliest form of all skin cancers and is one of the leading cancer diagnoses in the US. Its annual incidence has been rising steadily at a rate of $2.3 \%$ since 1975 for all races within the US. ${ }^{1}$ Light-skinned individuals are physiologically at a higher risk for melanoma than their dark-skinned counterparts. ${ }^{2}$ Thus, much of the medical literature, current research, and public health efforts have targeted the Caucasian population as the gold standard for the development of prevention and treatment guidelines. Nevertheless, studies report that when African-Americans (AA) do develop melanoma, they tend to have more advanced tumors and poorer survival rates than Whites. ${ }^{2-6}$ The phenomenon of lower incidence but higher mortality among AA melanoma patients is herein described as the melanoma paradox.

High rates of advanced melanoma among AA have been attributed to a number of individual and societal factors leading to a disparity in secondary prevention. Few studies address how cultural differences and historical discrimination may influence melanoma awareness, and preventive behaviors among this group. This review focuses on describing the melanoma paradox by focusing on the current data on cutaneous
Correspondence: Alina Goldenberg San Diego Health System, University of California, One Miramar Street, La Jolla, CA 92092, USA

Tel +l 415846429 I

Email a Igolden@ucsd.edu 
melanoma among AA within the US, the epidemiologic differences in melanoma severity by race, and possible attributable factors to the growing paradox of melanoma within minorities - lower incidence, but higher deaths.

\section{Definition of AA within the US}

The US AA population is a diverse, heterogeneous group with origins spanning the US, and various African and Afro-Caribbean countries. Due to racial admixing, ${ }^{7}$ this population also has European and Native American ancestry. ${ }^{8}$ Based on the latest US census data, AA comprise the second most populous racial minority group representing $13.6 \%$ of the US population. ${ }^{9}$ This population group is expected to grow at a $7 \%$ rate per year. As the Fitzpatrick Skin Type Classification scale was developed based on White patient data, its validity within the AA population has been questioned as it often overestimates the prevalence of skin type Fitzpatrick IV among AA. ${ }^{10}$ Thus, due to the heterogeneity of the AA group, their skin may be categorized as varying between Fitzpatrick III and VI.

\section{Melanoma risk factors}

Melanoma is a skin cancer derived from the pigment-producing melanocytes. Melanoma risk factors include both environmental and genetic factors. Intermittent ultraviolet (UV) exposure is a major cause of melanoma. History of childhood blistering sunburns, used as a surrogate measurement for intermittent sun exposure, is a significant independent risk factor for melanoma development. ${ }^{11}$ People with light skin pigment, denoted by the Fitzpatrick skin types I and II, have significantly increased tendency to sunburn and this is associated with increased melanoma risk. ${ }^{12,13}$ However, if melanin was solely sufficient for melanoma protection, a perfect negative linear slope would exist in a graphical depiction of melanoma incidence and skin color. Thus, secondary risk factors for melanoma among non-Whites continue to be elucidated, as UV exposure is believed to play a smaller role in melanoma development in these groups. ${ }^{14,15}$

The quantity (more than 100 for adults and 50 for children) and quality (atypical or dysplastic) of nevi is a strong melanoma risk factor, as some melanomas arise from moles. ${ }^{16}$ Whites have the highest median number of nevi, followed by Hispanics, Asians, and Blacks. ${ }^{16}$ Studies propose that more than $90 \%$ of AA have at least one nevus, and they are predominantly acral. ${ }^{17}$ A retrospective review of 462 adults seen within the US outpatient dermatology clinic setting reported that palmar or plantar nevi were most common in AA $(3.4 \%$ vs $0.6 \%$ in whites) and the prevalence of these nevi directly increased with pigmentation degree $(P<0.001) .{ }^{18}$ Family history of a first-degree relative with melanoma doubles the melanoma risk; however, this may be attributed to similar genetic predisposition, environmental sun exposure, and skin characteristics (pigment, number of nevi, and sunburn predication). ${ }^{19}$

Genetic mutations within the cyclin-dependent inhibitor 2A tumor suppressor gene on chromosome 9p21 accounts for $40 \%$ of hereditary melanoma and a known mutation carries a $76 \%$ chance of developing melanoma. ${ }^{20}$ Mutations in the $B R A F$ gene have been reported in $66 \%$ of melanomas. ${ }^{21}$ Interestingly, genetic mutations tend to favor certain locations for melanoma. BRAF-mutated tumors tend to occur on skin subject to high intermittent sun exposure, whereas mutations in the tyrosine kinase receptor KIT are associated with melanomas from acral and mucosal sites. ${ }^{22}$

\section{The melanoma paradox Incidence}

Overall, the current reported lifetime incidence of cutaneous melanoma is 2.05\% among US Caucasians and 0.09\% among AA. ${ }^{1}$ According to Surveillance Epidemiology and End Result (SEER) population-based data from 1992 to 2011, the average annual percentage change of invasive cutaneous melanoma for non-Hispanic AA males and females was $0.6 \%$, whereas for Caucasian males and females it was $1.5 \%$ and $1.8 \%$, respectively. ${ }^{1}$ Overall, the incidence of invasive cutaneous melanoma for all races and sexes has decreased between 2010 and 2011 (24.02 vs 23.21 per 100,000). ${ }^{1}$ However, when the age-adjusted incidence is stratified by race, AA experienced a much smaller decline in incidence (1.04-1.03 per 100,000) as compared to Whites (29.18-27.79 per 100,000). ${ }^{1}$ Additionally, AA females showed an increase in age-adjusted incidence of cutaneous melanoma from 0.97 to 1.08 per 100,000 between 2010 and $2011 .{ }^{1}$ Overall, the White-to-AA incidence ratio for melanoma for both sexes in 2011 was $27.79: 1.03$ (per 100,000). ${ }^{1}$

\section{Survival}

Overall mortality rates for cutaneous melanoma among all races and sexes within the US have stabilized to 2.69 per 100,000 (age adjusted) in 2011. ${ }^{1}$ However, the age-adjusted mortality in AA females has risen from 0.35 to 0.41 between 2009 and $2011 .^{1}$ The 5-year relative survival from cutaneous melanoma among Whites between 2004 and 2010 was $92.9 \%$ for both sexes, whereas for AA (both sexes) it was $75.1 \%{ }^{1}$ This difference is most evident among White and Black males for which the 5-year relative survival between 2004 and 2010 was $91 \%$ vs $64.9 \%{ }^{1}$ When the cutaneous 
melanoma is stratified by stage, AA continue to have poorer survival: for localized tumors, between 2004 and 2010, the survival for Whites of both sexes was $98 \%$, whereas for AA it was $91 \%$, and for regional metastasizing tumors $62.6 \%$ vs $56.4 \%$, respectively.

This survival trend is evident in other regionally based literature. A retrospective review of 36 AA patients treated between 1981 and 2000 in Washington, DC, found that the 5-year survival was $58.8 \%$ for AA as compared to $84.8 \%$ in Whites. ${ }^{4}$ Moreover, studies report that AA have more advanced tumors at presentation than Whites., ${ }^{4,23}$ The 5-year review from the Washington, DC, showed a mean Breslow depth on presentation of $2.75 \mathrm{~mm}$ for AA and $1.16 \mathrm{~mm}$ for Whites. ${ }^{4}$ The 5 -year review of patients in Miami-Dade County showed that non-Hispanic Whites had the highest percentage of in situ (Clark's level I or stage 0) tumors while nonHispanic Blacks had the lowest - 27\% vs $10 \%$, respectively. ${ }^{24}$ Distant-metastasizing melanoma (Clark's level V or stage IV) diagnoses were more prevalent among minority patients than Caucasian patients $-31 \%$ vs $9 \%$, respectively. ${ }^{24}$ Studies show that predilection for advanced tumors also exists in Africans, with a mean reported Breslow depth on initial presentation of $6.15 \mathrm{~mm} .^{25}$

Thus, despite lower incidence rates and protective aspects of darker pigmentation, studies ranging from 1982 to 2013 consistently report that AA have higher rates of more advanced melanomas and lower overall survivals., 2,-6,23,26-31

\section{Location of melanoma}

Melanomas in AA groups commonly occur on non-sunexposed skin where there is less pigment, and thus, less melanin to protect the melanocytes from the mutagenic UV radiation. Out of all of the melanomas in AA, 60\%-75\% arise on the palms, soles, mucous membranes, and subungual regions, otherwise known as acral surfaces. ${ }^{32}$ In the retrospective review of 36 AA treated in Washington, DC, the most common location for a primary tumor was the foot $(38.9 \%){ }^{4}$ These patterns are consistent with those seen in African countries. A retrospective review of dermatologic malignancies within South Nigeria reported five cases of melanoma, and all of them being on the foot. ${ }^{33}$ An analysis of 844 South African patients found that one third was plantar. ${ }^{34,35}$ Additionally, the 1979 review showed that Blacks from Africa had a similar incidence of acral melanoma as those from the US despite varying shoe-wearing habits, ${ }^{36}$ suggesting a common secondary risk factor other than UV exposure.

Overall, acral lentiginous melanoma (ALM) is the most common histologic type among Blacks, both within the
US and in Africa. ${ }^{4,25,26,28,34,37-39}$ A study analyzed SEER data from 1986 to 2005 and found 1,413 confirmed ALMs; AA had the greatest proportion of ALMs (36\%) and ALMs had the lowest 5- and 10-year survival rates than all cutaneous melanoma types combined (80.3\% and $67.5 \%$ vs $91.3 \%$ and $87.5 \%$, respectively). ${ }^{39}$ Within the study, authors reported the 5- and 10-year melanoma-specific survival rates for ALMs with results showing that the highest survival rates were in non-Hispanic Whites (82.6\% and 69.4\%), intermediate in AA (77.2\% and 71.5\%), and lowest in Hispanic Whites $(72.8 \%$ and $57.3 \%$ ). These differences, however, were not statistically significant when controlled for tumor thickness or stage, and was consistent with other studies. ${ }^{39}$

Mucosal melanomas do not present with such differences between AA and Whites. Overall, the White:Black incidence ratio for vulvar and vaginas melanomas was found to be 3.14:1 and 1.02:1, respectively. ${ }^{40}$ The overall incidence ratio of mucosal melanomas of White:Black is 2.2-2.3:1. ${ }^{40}$ However, uveal melanoma also greatly differs between Whites and AA - an analysis of cases reported by SEER between 1992 and 2000 shows that the age-adjusted incidence ratio of White:Black was 18:1. ${ }^{41}$

\section{Barriers to health}

Societal, individual, and historical factors contribute to the melanoma paradox among AA within the US.

\section{Societal barriers}

Careful full-body skin examinations performed by skilled physicians on a regular (usually yearly) basis and routine self-examinations can improve the chances of early detection, and ultimately eradication of melanoma. ${ }^{42,43}$ Multiple studies have shown that minorities report having significantly less physician performed full-body skin examinations., , $^{3,44} 46$ Moreover, minorities were found to have significantly less ability to recognize a worrisome mole on self-examination. ${ }^{3}$ Suboptimal screening for melanoma among minorities, both through physician and self-examination, has led to the unequal morbidity and mortality burdens seen with melanoma outcomes. Moreover, current US Preventive Services Task Force still does not recommend screening full-body skin examination (self or professional) because it concluded that the evidence for its benefits are inconclusive. ${ }^{47}$ This lapse in public health education policy has allowed gaps in melanoma awareness, diagnosis, and treatment.

Self-perception of melanoma risk among minorities is low. ${ }^{48}$ Public education efforts targeting skin cancer have focused on the high-incidence White populations, 
developing an unspoken misperception that since minorities are not targeted, they must not be at risk. Robinson et al showed that minorities were surprised to learn that melanoma was not only a type of skin cancer but also they were at risk for it. ${ }^{49}$ Moreover, less health care access among minorities has led to less physician-driven education on skin cancer awareness, self-examination instruction, and risky behavior avoidance.

\section{Individual barriers}

Education, through public infrastructure, physician counseling, and media, plays a role in patients' awareness of melanoma risk, signs, and screening tools. AA have higher high-school dropout rates than Whites, and overall they are more likely to attend high-poverty schools. ${ }^{50}$ Lack of a strong educational foundation contributes to diminished health literacy leading to difficulties in understanding physicians, inabilities to ask necessary questions, take control of one's own health, and ultimately, poorer health outcomes. ${ }^{51}$ This can contribute to the melanoma paradox as possibly a lack of health education may preclude some AA from clearly assessing their risk of melanoma, and understanding the importance of regular medical check-ups. ${ }^{48} \mathrm{AA}$ have double the unemployment rates to those of Whites with the US. ${ }^{52}$

Socioeconomic status can greatly affect ability to pay for and access care; moreover, it often affects the quality of care as well. Findings from the 2011 National Healthcare Quality and Disparities Report indicate significant differences in quality and access to care among minorities as compared to Whites. ${ }^{9}$ Blacks under the age of 65 were significantly less likely to have health insurance. ${ }^{9}$ Moreover, the percentage of Blacks with a specific source of ongoing medical care (such as a primary care physician) was lower than for Whites. ${ }^{9}$ Blacks have reported worse access to medical care than Whites. ${ }^{9}$ Also, as racial and ethnic minorities are more likely than Whites to be poor, overall poor people had worse access to care than high-income people. ${ }^{9}$ Thus, access and quality of medical care differs among minorities and may contribute to the melanoma disparity.

AA may have a predisposition for developing more aggressive, acral and mucosal melanomas. Melanomas in these sights may be intrinsically more aggressive leading to a primary presentation at a more advanced stage. ${ }^{4,6,25}$ Furthermore, when studies compared Blacks with Whites who had a melanoma of the same stage, and received medical treatment, survival was still shorter for Blacks possibly suggesting that the tumor growth in minorities is somehow intrinsically more virulent and aggressive. ${ }^{6}$ Moreover, the melanoma lesions within subungual, mucosal, and palmar areas on darker pigmented individuals can be very difficult to diagnose. Melanoma can mimic normal skin variations such as longitudinal melanonychia, and hyperpigmented macules and thus, be missed. ${ }^{53}$ Furthermore, as certain genetic mutations favor acral sites for melanoma growth, minorities may have a genetic predisposition for these tumors. More research is necessary to elucidate the etiologic importance of genes in the minority melanoma pathogenesis.

\section{Historical barriers}

Historical medical discrimination and mistreatment of minorities have led to widespread medical mistrust, perceived discrimination, and avoidance of health management and treatment among minorities. Negative historical events tracing to the days of slavery up to the 21 st century have led to the growth of health care mistrust among AA. During slavery, bodies of deceased Black slaves were used as subjects of medical experimentation and anatomic dissection, without the individual's or his/her family's consent. ${ }^{54}$ This continued even after the Civil War with grave robbing of bodies to feed medical school anatomy laboratories. ${ }^{55}$ Moreover, experimentation on living slaves was performed for drug treatments of heatstroke, and to perfect surgeries of vesicovaginal fistulas. ${ }^{56,57}$ However, the Tuskegee Study of Untreated Syphilis in the Negro Male (1932-1972) continues to be reported as a central event in the development of AA distrust of the medical system. ${ }^{58}$ Despite major regulation of research and health care targeting patient beneficence, autonomy, and justice, the mistrust of the medical community persists, especially among AA. ${ }^{59}$ Perceived racism in health care is also an important determinant of health care utilization. ${ }^{59}$ Via multiple focus groups, Collins et al showed that AA may anticipate unfair medical treatment and thus, avoid it. ${ }^{60}$ Health care mistrust often leads to hesitation and delays in diagnosis and treatment of various conditions including cancer; moreover, it limits adherence to physician recommendations. ${ }^{59}$ Although there are no specific studies examining the relationship of physician mistrust on melanoma survival and prevention adherence, the knowledge attained through other studies in other medical fields may be applied to dermatology. Thus, dermatologists must be aware of the historical and cultural issues of their AA patients. Lack of physician cultural competency may lead to poor rapport, mistrust, and lack of adherence to skin cancer prevention guidelines.

\section{Role of vitamin D}

Vitamin D is known to have anti-proliferative and proapoptotic effect on melanocytes and keratinocytes. In vitro 
studies of vitamin D found that it inhibits melanoma growth via regulation of cell proliferation, differentiation, and apoptosis. ${ }^{61,62}$ These functions are supported by the finding of vitamin D receptors within keratinocytes and melanocytes. ${ }^{63}$ Much literature has found supportive evidence for protective effects of vitamin D within various cancers ${ }^{64,65}$ and specifically melanoma. ${ }^{66-68} \mathrm{~A}$ case-control study of northern Italian patients found an inverse relationship between dietary vitamin D and melanoma risk. ${ }^{69} \mathrm{~A}$ meta-analysis of 20 articles, which included 1,420 cases of cutaneous melanoma, found an inverse association between vitamin D blood levels and melanoma thickness. ${ }^{70}$

AA have been reported to have lower mean serum vitamin D levels, ${ }^{71}$ and higher prevalence of hypovitaminosis D than Whites. ${ }^{72}$ This may be explained in that AA are biologically less efficient at producing vitamin D from UV radiation and have been found to have less vitamin D from dietary intake. ${ }^{73,74}$ Thus, this difference in vitamin $\mathrm{D}$ production and levels may play a role in the melanoma disparity between AA and Whites.

\section{Discussion}

Melanoma is one of the leading cancers worldwide. Although AA have a much lower incidence of cutaneous melanoma than Whites, they tend to develop more advanced tumors and ultimately have lower survival statistics. This disparity, herein termed the melanoma paradox, is an important reality in the field of melanoma and its causes are multifactorial.

Differences in education, socioeconomic status, access to and quality of care, lack of public health efforts promoting awareness and screening, general mistrust of the medical establishment, and lack of self-perception of risk contribute to the growing disparity in melanoma outcomes among minorities as compared to Whites. As ALMs are the most common melanoma type among AA, further larger studies evaluating the role of this melanoma subtype on cancer aggressiveness and patient overall survival are necessary.

Fortunately, greater awareness of this issue can prompt both individual and societal change. Primary prevention of melanoma, including reducing the number of new tumors through genetic screening and targeted treatments, decreases in UV exposure, and maintenance of a healthy immune system is a possible option for the long-term improvement in health. However, more practical approaches available now for at-risk patients involve secondary prevention methods, which include early diagnosis and treatment. Studies show that equal numbers of skin cancer patients utilize media and their physicians for health information. ${ }^{75}$ Thus, incorporating television, social media, and public billboard campaigns to increase the awareness for melanoma risk among minorities can be utilized as part of a larger public health campaign. Moreover, in order to lobby the US Preventive Services Task Force to promote screening as a beneficial tool to prevent skin cancer, further research must be done with focuses on minorities as important groups within skin cancer. With the establishment of the Affordable Care Act in the US, limitations to health care access will be diminished, thus allowing for a greater cohort of AA and other minorities to receive regular specialty care.

\section{Conclusion}

Overall, earlier diagnosis of melanoma among minorities is the main point of intervention, which can help to improve survival. Dermatologists and patients must assist in improving early diagnosis by maintaining a high index of suspicion despite statistical and individual perceptions of risk. Specifically, more extensive self- and physician-skin examinations focusing on the palms, soles, subungual areas, and the mucosa may be needed for AA in order to diagnose acral melanomas early. Through encouragement of individual education on skin cancer risk and detection, increased skin examination and risk perception, and the incorporation of discussions on culturally relevant barriers into the medical conversation, the melanoma paradox can begin to be concurred and, ultimately, overcome.

\section{Acknowledgments}

The project described was supported partially by the National Institutes of Health, Grant TL1 RR031979, and by the National Cancer Institute of the National Institutes of Health under award number K08CA155035, and the Melanoma Research Alliance. The authors are also grateful to Timothy Dattels for his generous support. The content is solely the responsibility of the authors and does not necessarily represent the official views of the National Institutes of Health.

\section{Disclosure}

The authors report no conflicts of interest in this work.

\section{References}

1. Howlader N, Noone AM, Krapcho M, et al, editors. SEER Cancer Statistics Review, 1975-2011. Bethesda (MD): National Cancer Institute; 2014. Available from: http://seer.cancer.gov/csr/1975_2011/, based on November 2013 SEER data submission, posted to the SEER web site, April 2014. Accessed April 1, 2015.

2. Wu XC, Eide MJ, King J, et al. Racial and ethnic variations in incidence and survival of cutaneous melanoma in the United States, 1999-2006. J Am Acad Dermatol. 2011;65(5 Suppl 1):S26-S37. 
3. Korta DZ, Saggar V, Wu TP, Sanchez M. Racial differences in skin cancer awareness and surveillance practices at a public hospital dermatology clinic. J Am Acad Dermatol. 2014;70(2):312-317.

4. Byrd KM, Wilson DC, Hoyler SS, Peck GL. Advanced presentation of melanoma in African Americans. J Am Acad Dermatol. 2004;50(1): 21-24; discussion 142-143.

5. Reintgen DS, McCarty KM Jr, Cox E, Seigler HF. Malignant melanoma in black American and white American populations. A comparative review. JAMA. 1982;248(15):1856-1859.

6. Bellows CF, Belafsky P, Fortgang IS, Beech DJ. Melanoma in AfricanAmericans: trends in biological behavior and clinical characteristics over two decades. J Surg Oncol. 2001;78(1):10-16.

7. Shriver MD, Parra EJ, Dios S, et al. Skin pigmentation, biogeographical ancestry and admixture mapping. Hum Genet. 2003;112(4):387-399.

8. Shoo BA, Kashani-Sabet M. Melanoma arising in African-, Asian-, Latino- and Native-American populations. Semin Cutan Med Surg. 2009;28(2):96-102.

9. Disparities in Healthcare Quality among Racial and Ethnic Groups. Selected Findings from the 2011 National Healthcare Quality and Disparities Reports. Fact Sheet. AHRQ Publication No 12-0006-1-EF, September 2012. Rockville (MD): Agency for Healthcare Research and Quality; 2012. Available from: http://www.ahrq.gov/qual/nhqrdr11/ nhqrdrminority11.htm. Accessed May 10, 2014.

10. Pichon LC, Landrine H, Corral I, Hao Y, Mayer JA, Hoerster KD. Measuring skin cancer risk in African Americans: is the Fitzpatrick Skin Type Classification Scale culturally sensitive? Ethn Dis. 2010; 20(2):174-179.

11. Elwood JM, Jopson J. Melanoma and sun exposure: an overview of published studies. Int J Cancer. 1997;73(2):198-203.

12. Veierod MB, Weiderpass E, Thörn M, et al. A prospective study of pigmentation, sun exposure, and risk of cutaneous malignant melanoma in women. J Natl Cancer Inst. 2003;95(20):1530-1538.

13. Titus-Ernstoff L, Perry AE, Spencer SK, Gibson JJ, Cole BF, Ernstoff MS. Pigmentary characteristics and moles in relation to melanoma risk. Int $J$ Cancer. 2005;116(1):144-149.

14. Elder DE. Skin cancer. Melanoma and other specific nonmelanoma skin cancers. Cancer. 1995;75(1 Suppl):245-256.

15. Armstrong BK, Kricker A. How much melanoma is caused by sun exposure? Melanoma Res. 1993;3(6):395-401.

16. Crane LA, Mokrohisky ST, Dellavalle RP, et al. Melanocytic nevus development in Colorado children born in 1998: a longitudinal study. Arch Dermatol. 2009;145(2):148-156.

17. Coleman WP 3rd, Gately LE 3rd, Krementz AB, Reed RJ, Krementz ET. Nevi, lentigines, and melanomas in blacks. Arch Dermatol. 1980;116(5): 548-551.

18. Palicka GA, Rhodes AR. Acral melanocytic nevi: prevalence and distribution of gross morphologic features in white and black adults. Arch Dermatol. 2010;146(10):1085-1094.

19. Niendorf KB, Tsao H. Cutaneous melanoma: family screening and genetic testing. Dermatol Ther. 2006;19(1):1-8.

20. Bishop DT, Demenais F, Goldstein AM, et al. Geographical variation in the penetrance of CDKN2A mutations for melanoma. J Natl Cancer Inst. 2002;94(12):894-903.

21. Davies H, Bignell GR, Cox C, et al. Mutations of the $B R A F$ gene in human cancer. Nature. 2002;417(6892):949-954.

22. Curtin JA, Busam K, Pinkel D, Bastian BC. Somatic activation of KIT in distinct subtypes of melanoma. J Clin Oncol. 2006;24(26):4340-4346.

23. Hu S, Parker DF, Thomas AG, Kirsner RS. Advanced presentation of melanoma in African Americans: the Miami-Dade County experience. J Am Acad Dermatol. 2004;51(6):1031-1032.

24. Hu S, Soza-Vento RM, Parker DF, Kirsner RS. Comparison of stage at diagnosis of melanoma among Hispanic, black, and white patients in Miami-Dade County, Florida. Arch Dermatol. 2006;142(6):704-708.

25. Hudson DA, Krige JE. Melanoma in black South Africans. J Am Coll Surg. 1995;180(1):65-71.

26. Cormier JN, Xing Y, Ding M, et al. Ethnic differences among patients with cutaneous melanoma. Arch Intern Med. 2006;166(17):1907-1914.
27. Hu S, Soza-Vento RM, Parker DF, Kirsner RS. Comparison of stage at diagnosis of melanoma among Hispanic, black, and white patients in Miami-Dade County, Florida. Arch Dermatol. 2006;142(6):704-708.

28. Cress RD, Holly EA. Incidence of cutaneous melanoma among nonHispanic whites, Hispanics, Asians, and blacks: an analysis of California cancer registry data, 1988-1993. Cancer Causes Control. 1997;8(2): 246-252.

29. Feun LG, Raub WA Jr, Duncan RC, et al. Melanoma in a southeastern Hispanic population. Cancer Detect Prev. 1994;18(2):145-152.

30. Black WC, Goldhahn RT Jr, Wiggins C. Melanoma within a southwestern Hispanic population. Arch Dermatol. 1987;123(10): 1331-1334.

31. Hu S, Parmet Y, Allen G, et al. Disparity in melanoma: a trend analysis of melanoma incidence and stage at diagnosis among whites, Hispanics, and blacks in Florida. Arch Dermatol. 2009;145(12):1369-1374.

32. Gloster HM Jr, Neal K. Skin cancer in skin of color. J Am Acad Dermatol. 2006;55(5):741-760; quiz 761-744.

33. Asuquo ME, Ngim O, Ugare G, Omotoso J, Ebughe G. Major dermatologic malignancies encountered in a teaching hospital surgical department in South Nigeria. Am J Clin Dermatol. 2008;9(6):383-387.

34. Swan MC, Hudson DA. Malignant melanoma in South Africans of mixed ancestry: a retrospective analysis. Melanoma Res. 2003;13(4): 415-419.

35. Miles A, Waller J, Hiom S, Swanston D. SunSmart? Skin cancer knowledge and preventive behaviour in a British population representative sample. Health Educ Res. 2005;20(5):579-585.

36. Crombie IK. Racial differences in melanoma incidence. Br J Cancer. 1979;40(2):185-193.

37. Sutherland CM, Mather FJ, Muchmore JH, Carter D, Reed RJ, Krementz ET. Acral lentiginous melanoma. Am J Surg. 1993;166(1): 64-67.

38. Nagore E, Pereda C, Botella-Estrada R, Requena C, Guillen C. Acral lentiginous melanoma presents distinct clinical profile with high cancer susceptibility. Cancer Causes Control. 2009;20(1):115-119.

39. Bradford PT, Goldstein AM, McMaster ML, Tucker MA. Acral lentiginous melanoma: incidence and survival patterns in the United States, 1986-2005. Arch Dermatol. 2009;145:427-434.

40. Hu DN, Yu GP, McCormick SA. Population-based incidence of vulvar and vaginal melanoma in various races and ethnic groups with comparisons to other site-specific melanomas. Melanoma Res. 2010;20(2):153-158.

41. Hu DN, Yu GP, McCormick SA, Schneider S, Finger PT. Populationbased incidence of uveal melanoma in various races and ethnic groups. Am J Ophthalmol. 2005;140(4):612-617.

42. Friedman RJ, Rigel DS, Kopf AW. Early detection of malignant melanoma: the role of physician examination and self-examination of the skin. CA Cancer J Clin. 1985;35:130-151. doi:10.3322/ canjclin.35.3.130

43. Aitken JF, Elwood M, Baade PD, Youl P, English D. Clinical wholebody skin examination reduces the incidence of thick melanomas. Int J Cancer. 2010;126(2):450-458.

44. Geller AC, Koh HK, Miller DR, Clapp RW, Mercer MB, Lew RA. Use of health services before the diagnosis of melanoma: implications for early detection and screening. J Gen Intern Med. 1992;7(2): $154-157$.

45. Coups EJ, Stapleton JL, Hudson SV, Medina-Forrester A, Goydos JS, Natale-Pereira A. Skin cancer screening among Hispanic adults in the United States: results from the 2010 national health interview survey. Arch Dermatol. 2012;148(7):861-863.

46. Andreeva VA, Cockburn MG. Cutaneous melanoma and other skin cancer screening among Hispanics in the United States: a review of the evidence, disparities, and need for expanding the intervention and research agendas. Arch Dermatol. 2011;147(6):743-745.

47. US Preventive Services Task Force. Screening for Skin Cancer, Topic Page. Rockville (MD): US Preventive Services Task Force; 2009. Available from: http://www.uspreventiveservicestaskforce.org/uspstf/ uspsskca.htm. Accessed April 1, 2015. 
48. Pollitt RA, Swetter SM, Johnson TM, Patil P, Geller AC. Examining the pathways linking lower socioeconomic status and advanced melanoma. Cancer. 2012;118(16):4004-4013.

49. Robinson JK, Joshi KM, Ortiz S, Kundu RV. Melanoma knowledge, perception, and awareness in ethnic minorities in Chicago: recommendations regarding education. Psychooncology. 2011;20(3):313-320.

50. National Center for Education Statistics. Education Longitudinal Study of 2002. Washington (DC): National Center for Education Statistics; 2002. Available from: http://nces.ed.gov/surveys/els2002/bibliography. asp. Accessed April 1, 2015.

51. Berkman ND, Sheridan SL, Donahue KE, Halpern DJ, Crotty K. Low health literacy and health outcomes: an updated systematic review. Ann Intern Med. 2011;155(2):97-107.

52. Rodgers WM. Understanding the Black and White earnings gap: why do African Americans continue to earn less despite dramatic gains in education? The American Prospect; 2008. Available from: http://prospect. org/article/understanding-black-white-earnings-gap. Accessed June 29, 2015.

53. Rahman Z, Taylor SC. Malignant melanoma in African Americans. Cutis. 2001;67(5):403-406.

54. Savitt TL. The use of blacks for medical experimentation and demonstration in the Old South. J South Hist. 48(1982):331-348.

55. Humphrey DC. Dissection and discrimination: the social origins of cadavers in America, 1760-1915. Bull N Y Acad Med. 49(1973):819-827.

56. Boney FN. Doctor Thomas Hamilton: two views of a gentleman of the Old South. Phylon. 28(1967):288-292.

57. Sims JM. The Story of My Life. New York: Appleton; 1889:236-237.

58. Gamble VN. Under the shadow of Tuskegee: African Americans and health care. Am J Public Health. 1997;87(11):1773-1778.

59. Hammond WP. Psychosocial correlates of medical mistrust among African American men. Am J Community Psychol. 2010;45(1-2): 87-106.

60. Collins TC, Clark JA, Petersen LA, Kressin NR. Racial differences in how patients perceive physician communication regarding cardiac testing. Med Care. 2002;40(1 Suppl):I27-I34.

61. Evans SR, Houghton AM, Schumaker L, et al. Vitamin D receptor and growth inhibition by 1,25-dihydroxyvitamin D3 in human malignant melanoma cell lines. J Surg Res. 1996;61(1):127-133.

62. Osborne JE, Hutchinson PE. Vitamin D and systemic cancer: is this relevant to malignant melanoma? Br J Dermatol. 2002;147(2):197-213.
63. Tang JY, Fu T, Lau C, Oh DH, Bikle DD, Asgari MM. Vitamin D in cutaneous carcinogenesis: part II. JAm Acad Dermatol. 2012;67(5):817. e1-817.e11; quiz 827-828.

64. Davis CD. Vitamin D and cancer: current dilemmas and future research needs. Am J Clin Nutr. 2008;88(2):565S-569S.

65. Grant WB, Peiris AN. Differences in vitamin D status may account for unexplained disparities in cancer survival rates between African and white Americans. Dermatoendocrinol. 2012;4(2):85-94.

66. Weinstock MA, Moses AM. Skin cancer meets vitamin D: the way forward for dermatology and public health. J Am Acad Dermatol. 2009;61(4):720-724.

67. Egan KM. Vitamin D and melanoma. Ann Epidemiol. 2009;19(7): 455-461.

68. Godar DE, Landry RJ, Lucas AD. Increased UVA exposures and decreased cutaneous vitamin $\mathrm{D}(3)$ levels may be responsible for the increasing incidence of melanoma. Med Hypotheses. 2009;72(4): 434-443.

69. Vinceti M, Malagoli C, Fiorentini C, et al. Inverse association between dietary vitamin $\mathrm{D}$ and risk of cutaneous melanoma in a northern Italy population. Nutr Cancer. 2011;63(4):506-513.

70. Caini S, Boniol M, Tosti G, et al. Vitamin D and melanoma and nonmelanoma skin cancer risk and prognosis: a comprehensive review and meta-analysis. Eur J Cancer. 2014;50(15):2649-2658.

71. Ginde AA, Liu MC, Camargo CA Jr. Demographic differences and trends of vitamin D insufficiency in the US population, 1988-2004. Arch Intern Med. 2009;169(6):626-632.

72. Egan KM, Signorello LB, Munro HM, Hargreaves MK, Hollis BW, Blot WJ. Vitamin D insufficiency among African-Americans in the southeastern United States: implications for cancer disparities (United States). Cancer Causes Control. 2008;19(5):527-535.

73. Harris SS. Vitamin D and African Americans. J Nutr. 2006;136(4): 1126-1129.

74. Nesby-O'Dell S, Scanlon KS, Cogswell ME, et al. Hypovitaminosis $\mathrm{D}$ prevalence and determinants among African American and white women of reproductive age: third National Health and Nutrition Examination Survey, 1988-1994. Am J Clin Nutr. 2002;76(1):187-192.

75. Goldenberg A, Nguyen BT, Jiang SI. Knowledge, understanding, and use of preventive strategies against nonmelanoma skin cancer in healthy and immunosuppressed individuals undergoing Mohs surgery. Dermatol Surg. 2014;40(2):93-100.
Clinical, Cosmetic and Investigational Dermatology

\section{Publish your work in this journal}

Clinical, Cosmetic and Investigational Dermatology is an international, peer-reviewed, open access, online journal that focuses on the latest clinical and experimental research in all aspects of skin disease and cosmetic interventions. All areas of dermatology will be covered; contributions will be welcomed from all clinicians and

\section{Dovepress}

basic science researchers globally. This journal is indexed on CAS. The manuscript management system is completely online and includes a very quick and fair peer-review system, which is all easy to use. Visit http://www.dovepress.com/testimonials.php to read real quotes from published authors. 